\title{
Patterns of verbal interaction and student satisfaction within a clinical setting: a video-enhanced observational study
}

Field, J C

Zhang, E

Milke, $\mathrm{V}$

McCance, $S$

Worts, C

Stone, S J

Edwards, D C

\section{Introduction}

Clinical educators working within a state-managed healthcare system are faced with the challenge of providing a quality teaching experience for students, whilst at the same time, ensuring quality of care and appropriate levels of service provision for the population. This requires close integration with University and state-funded resources; achieving a balance is critical to the success of both organisations. In addition to this challenge, the increasingly competitive global higher education sector recognises the impact of a strong student voice, meaning that student satisfaction is under additional scrutiny - and very much on the agenda of education providers; in fact, both the importance of the student's voice, and their satisfaction, is recognised within the new Graduating European Dentist curriculum (I).

The educational experience of the clinical encounter has the potential to be extremely valuable for students - an opportunity to problem solve and experiment, under the guidance of subject-matter-experts or experienced clinicians, that is almost unique to Dentistry. However, in addition to the professional and organisational constraints mentioned above, clinical teaching staff must also ensure that students have the opportunity to fully engage with, and reflect upon each patient encounter. The challenge for educators is in ensuring that they are providing a clinical teaching experience, not simply the clinical supervision of patient treatment.

Typically, school teachers verbally dominate the classroom, and this may lead to students being passive and dependent $(2,3)$. However, despite an abundance of learning theories and direction from educational institutions, the reality is that only a little is known about how clinical teachers actually teach (4). Some elements are key to the effectiveness of practical teaching (positive reinforcement, a positive atmosphere, higher-order questioning and 
feedback) (5), and in order to ensure a professional approach on the clinics, students should be encouraged to adopt an adult learning style. Sahlberg suggests that this development is unlikely with an overly dominant teacher, or with educational policies that hinder a flexible approach (6). Indeed it has been shown that encouraging further student participation, through peer to peer interaction and active questioning, can significantly and positively nurture these professional attributes (7). Foster (8) has shown that in medical education, although the level at which students are engaged correlates with their performance, regression analysis showed that interaction style contributes little to outcomes. Perhaps this is an indication that a generic teaching approach has certain limitations, and that in order to maximise learning potential, there is a need to relate to individual student preferences. This ability for a teacher to be flexible and differentiate individual or smaller-group needs has been referred to as 'quality of influence' (9).

Studies investigating this 'quality of influence' have identified 'praise' as an important indicator for student satisfaction. Indeed, Burnett (10) observed 747 pupils across 6 elementary schools in Australia, and found that satisfied students received more praise and less negative teacher feedback. Further studies reinforce this finding across disciplines and ethnic groups $(1 \mathrm{I}, 12)$, although there is currently no available evidence for this association in older students or adult learners, whose learning styles and needs may be quite different. Further, no literature currently reports the relationship between individual student-clinician interaction and satisfaction, and national-level or individual course surveys are not specific or detailed enough to gather meaningful data about this particular interaction.

The aim of this study, therefore, was to investigate the relationship between patterns of verbal interaction, and individual student satisfaction, during dental clinical teaching encounters.

\section{Methods}

Patterns of verbal interactions between Stage 2 (BDS and Hygiene and Therapy, $n=86$ ) students, and their clinical teaching staff, were recorded within a clinical skills environment for one term (April to July) in a Dental School in the United Kingdom. Verbal Interaction Analysis (VIA) (9) was used as a basis for recording full verbal interactions between students and skills teachers and this is described below. 
Verbal interaction analysis (VIA)

VIA is based on an observational template that records the style of interaction, rather than the content of the conversation. The record is temporal, allowing more detailed analysis to be carried out that further qualifies the interactions. Originally, the VIA was used within primary schools to observe at 3-second intervals over a 20-minute period. Clinical interactions are much shorter, but other researchers have shown that the analysis is still valuable, even with 3-minute interactions (4). The observation procedure relies on an observer detailing the type of verbal interaction between student and teacher over a regular period during the encounter (typically 3 seconds). Relevant types of verbal interaction were modified from the original VIA, and are displayed in Table I.

\begin{tabular}{|c|c|c|c|}
\hline \multirow{7}{*}{$\begin{array}{l}\text { Teacher } \\
\text { talk }\end{array}$} & \multirow{4}{*}{$\begin{array}{l}\text { Indirect } \\
\text { influence }\end{array}$} & 1 & $\begin{array}{l}\text { Accepts feelings and tone of student in a non-threatening } \\
\text { manner, including predicting feelings or showing empathy }\end{array}$ \\
\hline & & 2 & $\begin{array}{l}\text { Praise or encouragement, including minor cues such as } \\
\text { 'um hum' and 'go on', positive reinforcers such as well- } \\
\text { done/nodding }\end{array}$ \\
\hline & & 3 & $\begin{array}{l}\text { Accepting or using student ideas, or developing student } \\
\text { ideas with suggestions }\end{array}$ \\
\hline & & 4 & $\begin{array}{l}\text { Asking questions, with the intention that the students } \\
\text { answers - open or closed }\end{array}$ \\
\hline & \multirow{3}{*}{$\begin{array}{l}\text { Direct } \\
\text { influence }\end{array}$} & 5 & $\begin{array}{l}\text { Lecturing facts and opinions, or expressing own ideas, } \\
\text { asking rhetorical questions }\end{array}$ \\
\hline & & 6 & $\begin{array}{l}\text { Giving directions, with which the student is expected to } \\
\text { comply }\end{array}$ \\
\hline & & 7 & $\begin{array}{l}\text { Criticising or justifying authority, intended to change } \\
\text { student approach/behaviour }\end{array}$ \\
\hline \multirow{3}{*}{\multicolumn{2}{|c|}{ Student talk }} & 8 & $\begin{array}{l}\text { Student response, to a question or statement initiated by } \\
\text { the teacher }\end{array}$ \\
\hline & & 9 & $\begin{array}{l}\text { Student talk, initiated by the student themselves - question } \\
\text { or statement }\end{array}$ \\
\hline & & 10 & $\begin{array}{l}\text { Silence or confusion, in response to a question or request } \\
\text { by the teacher. Include periods of non-verbal \& non-clinical } \\
\text { activity }\end{array}$ \\
\hline \multicolumn{2}{|c|}{ Clinical observation } & 11 & $\begin{array}{l}\text { Clinical observation, involving the patient or patient } \\
\text { records/work or silence during core clinical activities such as } \\
\text { handwashing, or applying personal protective equipment }\end{array}$ \\
\hline
\end{tabular}

Table I - Types of verbal interaction recorded during the observations, modified from Flanders VIA (Flanders 1960)

Immediately following the clinical discussion, the student was asked to anonymously rate their satisfaction of the encounter using a 4-point scale (I - Very Satisfied, 2 - Satisfied, 3 Somewhat dissatisfied, 4 - Not at all satisfied). 
This study employed the use of a video-enhanced observational tool (VEO App, Veo-Group Ltd.) employed on an iPad Mini (Apple UK Ltd.) to record the verbal interactions (Figure I), the student satisfaction, and descriptive analysis of the data (Table 2). The video tool allowed real-time 'tagging' of observed behaviours, and temporal analysis of the encounter. A blurring function on the video allowed the equipment to be used within a clinical area, ensuring that participants and their surroundings were not readily identifiable from the video. The videos were uploaded securely to the VEO cloud server online, and analysed in order to provide descriptive information about the encounters.

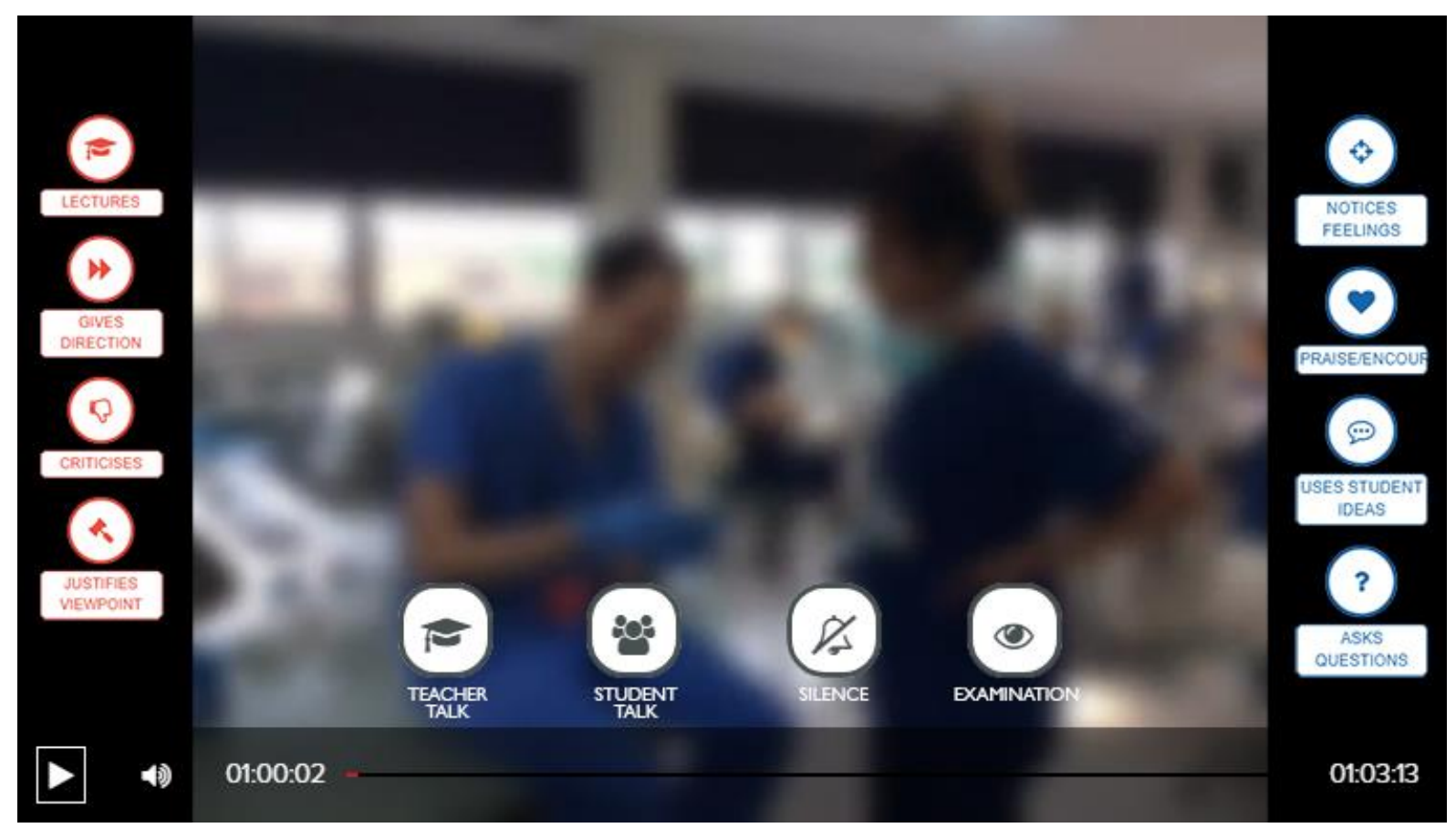

Figure I - Screenshot of the video-enhanced observation tool, allowing the real-time tagging of observed behaviours

\section{Data analysis}

Descriptive statistics were used to report overall levels of satisfaction. Correlation statistics were sought between satisfaction and the independent factors listed in Table 2. The statistical relationship between interaction characteristics and student satisfaction was analysed using a stepwise linear regression model with an entry criterion of 0.05 and a stay criterion of 0.1 (IBM SPSS Statistics for Windows, Version 25.0. Armonk, NY: IBM Corp). 


\begin{tabular}{|l|l|}
\hline Behaviour & Reporting method \\
\hline Accepts feelings and tone of the student & Frequency, correlation \\
\hline Praises or encourages & Frequency, correlation \\
\hline Accepts or develops student ideas & Frequency, correlation \\
\hline Asks questions & Frequency, correlation \\
\hline Lectures or gives opinion & Frequency, correlation \\
\hline Gives direction & Frequency, correlation \\
\hline Criticises & Frequency, correlation \\
\hline Justifies viewpoint & Frequency, correlation \\
\hline Teacher talk & \% of time, correlation \\
\hline Student talk & \% of time, correlation \\
\hline Silence & \% of time, correlation \\
\hline Examination & \% of time, correlation \\
\hline
\end{tabular}

Table 2 - Factors reported from the observational data

\section{Ethical considerations}

Although students should be encouraged to feed back about their clinical experiences, their clinical interactions wouldn't normally be examined so closely. This data is not routinely collected/available and as such, the BERA (British Educational Research Association 2014) guidelines suggest that this research was at sensitivity level 2 . When designing and implementing this study, the BERA guidelines were considered comprehensively. Favourable ethical approval was granted by Newcastle University (7898/20 I6).

\section{Results}

\section{Observations}

150 verbal interactions were recorded over the 4-month period, involving 7 different clinical teachers. The results for overall student satisfaction can be found in Table 3.

\begin{tabular}{|l|l|}
\hline Level of satisfaction & Number of students \\
\hline Very satisfied & 103 \\
\hline Satisfied & 36 \\
\hline Somewhat satisfied & 10 \\
\hline Not at all satisfied & $\mathrm{I}$ \\
\hline Total & 150 \\
\hline
\end{tabular}

Table 3 - Number of students reporting differing levels of satisfaction.

\section{Typical encounters}

Across the 150 observations, there was considerable heterogeneity in verbal interaction style. Table 4 reports mean values, ranges and correlation data. An example histogram for 
'time' (relating to the length of the encounter) is presented in Figure 2. An example scatterplot for 'gives direction' is presented in Figure 3.

\begin{tabular}{|l|c|c|c|c|}
\hline Factor & Mean value & Range & $\boldsymbol{B}$ & P value \\
\hline Accepts feelings and tone of the student & 0.5 & $0-8$ & 0.044 & $0.75 \mathrm{I}$ \\
\hline Praises or encourages & 3.2 & $0-10$ & 0.390 & $<0.000$ \\
\hline Accepts or develops student ideas & 1.3 & $0-8$ & 0.005 & $0.85 \mathrm{I}$ \\
\hline Asks questions & $4 . I$ & $0-24$ & $0.17 \mathrm{I}$ & 0.018 \\
\hline Lectures or gives opinion & 2.0 & $0-17$ & -0.085 & 0.658 \\
\hline Gives direction & 9.6 & 42 & $0.03 \mathrm{I}$ & 0.787 \\
\hline Criticises & $\mathrm{I}$ & $0-1 \mathrm{I}$ & -0.150 & 0.045 \\
\hline Justifies viewpoint & $\mathrm{I} .6$ & $0-12$ & -0.030 & 0.687 \\
\hline Teacher talk & $75.8 \%$ & $0-100$ & -0.019 & 0.659 \\
\hline Student talk & $16.6 \%$ & $0-100$ & $-0.23 \mathrm{I}$ & $<0.00 \mathrm{I}$ \\
\hline Silence & $\mathrm{I} .0 \%$ & $0-5 \mathrm{I}$ & -0.115 & 0.968 \\
\hline Examination & $6.7 \%$ & $0-92$ & 0.054 & 0.893 \\
\hline Total time & $\mathrm{I} 55.1$ seconds & $3 \mathrm{I}-557$ & 0.256 & $<0.00 \mathrm{I}$ \\
\hline
\end{tabular}

Table 4 - Descriptive and statistical analysis relating to the stepwise linear regression. The model had a $\mathrm{R}^{2}$ value of 0.269 and a $P$ value of 0.018 . Shaded rows indicate significant predictors of student satisfaction.

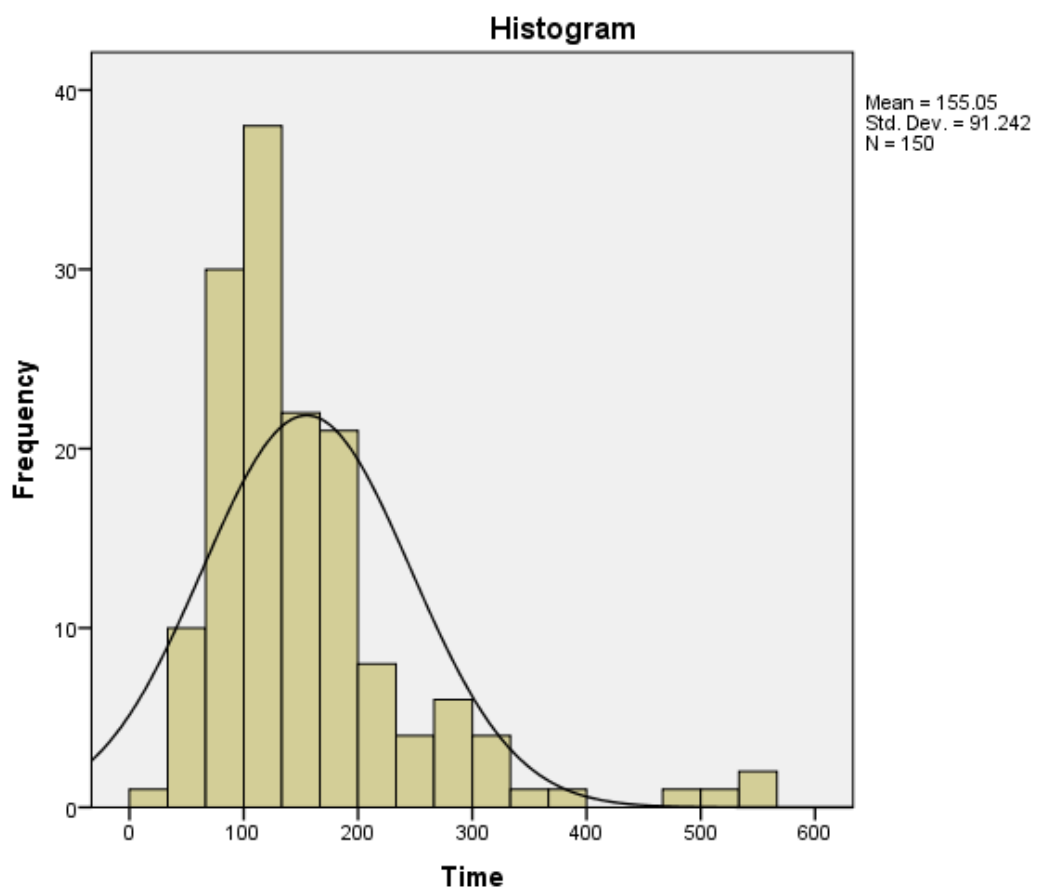

Figure 2 - Histogram for 'time' which represents the length of the clinical encounters, in seconds. 


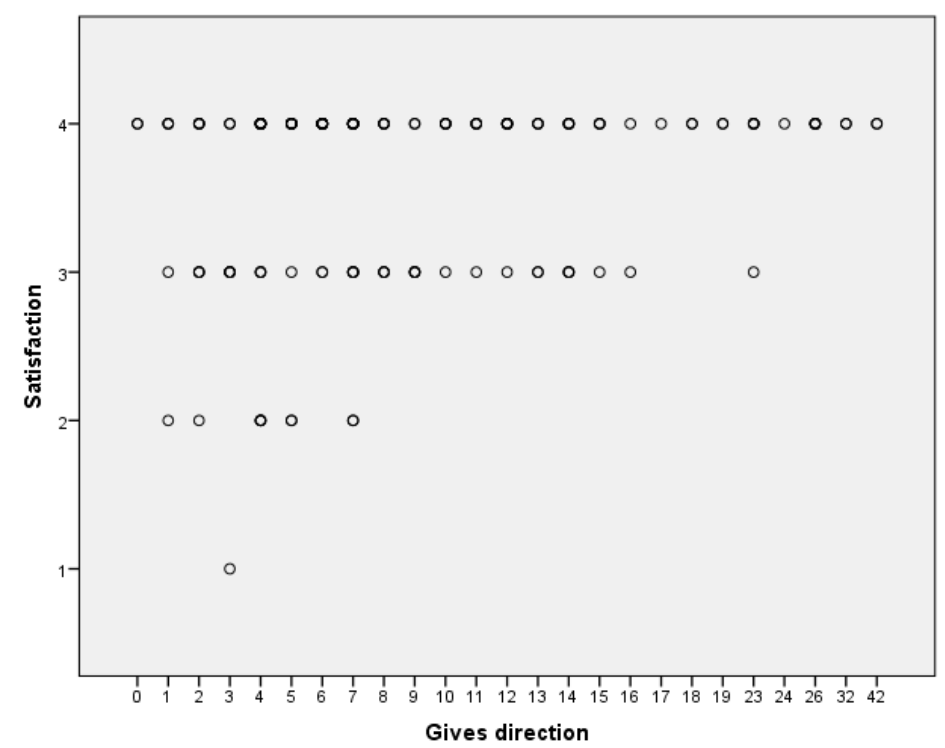

Figure 3 - Scatterplot for 'gives direction' against 'satisfaction' - $y$ axis represents the number of times that direction was given during each encounter (minimum 0 times, maximum 42 times)

\section{Predictors of satisfaction}

The stepwise linear regression showed that when 'satisfaction' was predicted, the length of the encounter $(B 0.256, P<0.00 I)$, the amount of praise/encouragement ( $B 0.390, P<0.000)$, the level of criticism ( $(B-0.150, P=0.045)$, the number of questions asked $(B 0.171, P=0.018)$, and the proportion of student talk $(B-0.23 \mathrm{I}, \mathrm{P}<0.00 \mathrm{I})$, were significant predictors.

The proportions of time spent with the teacher talking ( $B-0.019, P=0.615)$, time spent in silence $(B-0.115, P=0.968)$, and time spent examining the patient or clinical work ( $(B 0.054$, $\mathrm{P}=0.893)$, were not significant predictors of student satisfaction. Further, the degree to which the teacher lectured $(B-0.085, P=0.658)$, or gave direction $(B 0.031, P=0.787)$, was not a significant predictor of student satisfaction.

\section{Discussion}

It is clear that the majority of the students (69\%) were 'Very Satisfied' with their clinical teaching encounter. At least this is reassuring; however in isolation this data provides no information relating to why certain students were not 'Very Satisfied'. Indeed $8 \%$ were only 'somewhat satisfied' or 'Not at all satisfied' with their encounter and this will be discussed further below. 
Student satisfaction during each clinical encounter

The findings from this study reinforce the work by Irby and Chambers $(13,14)$ in that active involvement and apparent enthusiasm of the teacher, results in higher student satisfaction. Whilst operating as constructivist learners, the students are expected show a degree of internal motivation - and the teacher should facilitate the learning encounter, enabling the student to function in their zone of proximal development (I5). This is a social process, with a dynamic interaction between both parties. It could be argued, that the behavioural relationship between teacher and student directly influences the students' clinical 'quality of life'. This is reinforced by the work of Thorp and Baker $(I I, 12)$. Perhaps it is the case that interaction should be tailored individually, in order to improve satisfaction - this kind of interaction was reported by Hitz (I6) who highlighted the importance of recognising students' individual feelings, and this is primarily because some students value interactions differently (17). To a degree, student satisfaction then becomes about the emotional intelligence of the teacher - very much a dynamic process that is dependent on the behaviour of both parties.

Patterns of verbal interaction during each clinical encounter

The majority of the observations in this study were heavily 'teacher-centred', with a mean proportion of teacher talk, of $76 \%$; this reinforces the findings from Blatt (18) with medical students and their supervisors. This finding is unsurprising, especially given that the majority of these encounters took place in a simulation environment, where students were receiving feedback on procedures for which they had little experience, or were carrying out for the first time. This study also shows a strong correlation between praise and other positive teacher interventions, and student satisfaction. This reinforces the work by Burnett (I0) in the school classroom; although this data now provides evidence for the association within a higher education environment. Praise is clearly a subjective attribute; and Crow and Hitz (I6, 19) have previously attempted to qualify the required elements, concluding that they must be sincere, and encourage self-esteem whilst recognising the students' feelings. Findings in this study appear to reinforce the work carried by Chambers (13). Chambers investigated which characteristics dental students and staff felt were important during clinical interactions. Important factors included a motivating attitude, good communication skills, constructive criticism, the explanation of difficult concepts simply, enthusiasm, fairness, and a clinician who 
is interested, compassionate and proactive. Our findings correlate with the description of effective teachers by Rogers, including caring about students, empathy and genuineness (20).

The time that students spent in silence or confusion could be considered the antithesis to praise - this time is often uncomfortable for the student, and arguably wasted. There is also a concern that the student may appear in a bad light before the patient and this may negatively affect the subsequent student-patient interaction. The findings from this study showed a negative correlation between satisfaction and silence - although this was not significant.

The data in this study show no significant correlation for overall satisfaction with the proportion of teacher talk. This finding is particularly interesting, because it is often purported that a poor clinical encounter will involve excessive teacher talk at the expense of student participation, or be overly brief or extensive. When we consider student participation, this study showed a significant negative correlation with satisfaction. Perhaps students expect a more unilateral encounter from their teachers - and it should be noted that this study reports their levels of satisfaction, not the actual effectiveness of the encounter. Flanders (2) claims that an effective teacher is able to convey an education message, whilst motivating the student and providing a framework to support their participation; in essence this captures the complexities of clinical teaching, which necessarily involves accepting, clarifying, praising and developing the students on an individual level.

\section{Interactions and statistical modelling}

The scatterplot in Figure 3 shows a higher degree of variation within the 'very satisfied' group. This is a common feature across most of the observed domains - and this further reinforces the concept that some students will value interactions differently; however, it is also highly likely that there are compound effects and interactions from other external factors. A further complicating factor is that of perceived value; students may not perceive that an encounter has contained certain elements that the observer has recorded. There is likely to be an inherent bias with the observer; either with their own preconceptions or with the teacher's intent. It is also likely that the existing relationship that the clinician has with the student may result in differing perceptions of quality, although this was not 
investigated within this study. It is therefore important to know your student and appreciate how they like to be engaged. Flanders (9) stated that in a classroom, verbal communication is predominant. In a clinical setting this may still be the case, dependent on the stage of clinical interaction. However, as the students' knowledge and experience increases, they may move more towards the centre of their community of practice, and we would expect to see reduced verbal input from the clinical supervisor (2I).

Cantor (17) warns of making assumptions based on these generic findings. Students may often value learning opportunities and teaching interactions differently, not only to their teachers but also to their peers. No literature details this interaction in relation to clinical teaching; indeed what literature does exist investigates the interaction between student satisfaction and the delivery of feedback rather than the overall clinical encounter. This may well be a function of the teaching encounter within medical education, both within the US and the UK; the true patient encounter that involves supervised treatment only really happens in Dentistry at an undergraduate level. Nonetheless, satisfaction with the overall encounter is valuable information, not least as feedback for the educators themselves. One of the biggest problems within education is recording a valid assessment of the quality of teaching. At best this will provide a snapshot of the students' perceptions if recorded immediately, or an indirect measure through performance later on during the period of study. The former is subject to bias from the immediacy and emotion of the situation; the latter due to interpretation and wider perceptions. Robins (22) refers to the last point, in that when students are asked about satisfaction, they may well consider factors out with the immediate intended remit, such as 'time taken to deliver feedback', 'course organisation' or 'accessibility of facilities'. Indeed Wubbels (23) noted that students who held positive relationships with teachers also perceived the environment in a more positive way.

Teachers vs. teaching

Through earlier discussion we have seen that the way in which a teacher engages the students can directly affect the satisfaction rating; but are students able to truly differentiate between the 'teacher' and their 'teaching'. For example, how 'nice' a teacher is, or the 'level' of marks that they are accustomed to giving may influence evaluations, despite having a robust assessment tool. This is about student perceptions and it is for that reason that the authors feel that we should ask about the teaching 'episode or encounter' rather than asking students 
to rate the 'teacher'. This idea is again supported by Robins (22) who questioned 430 students about satisfaction at University of Michigan Medical School; some factors were objective such as timely feedback but some also made subjective judgements about the teacher(s).

The one-minute teacher

It is useful to draw together the findings from this, and other studies, in order to make recommendations for effective clinical teaching. Several models for good clinical teaching do already exist. Possibly the most well-know is the 'one-minute teacher' (24). The concept is outlined below in Table 5. The recommendations reinforces our findings, that the encounter must be interspersed with praise and positive reinforcement in order for students to rate their experience as highly satisfactory. We have made some additional suggestions to this model (in green) based on the findings from this observational study.

\begin{tabular}{|c|c|}
\hline Stage & Description of the ideal clinical encounter \\
\hline $\mathrm{I}$ & Get a commitment from the student - ask an open question \\
\hline 2 & $\begin{array}{l}\text { Probe for supporting evidence or rationale - delve a little deeper with } \\
\text { closed question(s) and praise good responses or ideas }\end{array}$ \\
\hline 3 & $\begin{array}{l}\text { Teach general rules or procedures - or investigate, reinforce and develop } \\
\text { student ideas. Mediate the discussion rather than either party dominating it }\end{array}$ \\
\hline 4 & Reinforce what was correct - explore ideas, praise where possible \\
\hline 5 & Correct mistakes - but don't be too critical \\
\hline 6 & $\begin{array}{l}\text { Identify next learning steps - give some guidance, and opportunity for } \\
\text { questions }\end{array}$ \\
\hline
\end{tabular}
are in green.

Limitations and bias

A degree of bias may have been present by students being asked to rate their clinical encounter immediately: in this sense, the student's emotional state may override the assessment, as previously reported by Robins and Wubbels $(22,23)$. Although there is some evidence to suggest that teacher behaviour may change when being observed, there is little 
evidence to suggest that their verbal interaction with the student does (25). Fortunately, clinical students and teachers are often accustomed to being observed by other members of staff on a regular basis - and so an overt, naturalistic style was still considered appropriate. There may also be significant cultural variation in how the interaction between student and teacher takes place, and this was not explored within this single-site study.

\section{Conclusion}

This study aimed to determine if patterns of verbal interaction between dental clinicians and dental students affected the student satisfaction. The modified Flanders verbal interaction analysis tool appeared to be a useful method of assessing the clinical encounter.

The data suggest that a number of observed behaviours correlate significantly with increased satisfaction - such as the length of the encounter, the amount of praise delivered, the number of questions asked, the amount of criticism provided, and the proportion of time for which the student was speaking.

Praise and the acceptance of student ideas are required to offset any criticism, and the encounter seems to require structure from the clinician with an emphasis on indirect influence rather than just lecturing.

\section{Acknowledgements}

This study was carried out as a participatory action research project involving a number of third and fourth year BDS students - some of whom also co-authored the paper 


\section{References}

1. Field JC, Cowpe JG, Walmsley AD. The Graduating European Dentist: A New Undergraduate Curriculum Framework. European Journal of Dental Education. 2017;21:210.

2. Flanders N. Intent, Action and Feedback: A preparation for teaching. Journal of Teacher Education. 1963;14(3):251-60.

3. Schiro MS. Curriculum Theory: Conflicting Visions and Enduring Concerns: Sage, Los Angeles; 2013.

4. Sahlberg P, editor The more you talk, the more you learn: Missing conditions for cooperative learning in secondary schools. Conference for Cooperative learning in multicultural societies: critical reflections; 2008; Turin, Italy.

5. Wahlberg HJ. Synthesis of Research on Teaching. In: Wittrock CM, editor. Handbook of research on teaching. New York: Paragon; 1986.

6. Sahlberg P, Boce E. Are teachers teaching for a knowledge society? Teachers and Teaching. 2010;16(1):31-48.

7. Smith DG. College classroom interactions and critical thinking. Journal of Educational Psychology. 1977;69(2):180-90.

8. Foster PJ. Verbal participation and outcomes in medical education. A study of thirdyear clinical discussion groups. Annual Conference on Research in Medical Education Conference on Research in Medical Education. 1979;18:233-8.

9. Flanders NA. Teacher influence, pupil attitudes, and achievement; final report. Minneapolis: University of Minnesota; 1960. 1 v. (various pagings) $p$.

10. Burnett PC. Teacher Praise and Feedback and Students' Perceptions of the Classroom Environment. Educational Psychology. 2002;22(1):5-16.

11. Baker JA. Teacher-Student Interaction in Urban At-Risk Classrooms: Differential Behavior, Relationship Quality, and Student Satisfaction with School. Elementary School Journal. 1999;100(1):57-70.

12. Thorp HS, et al. Assessing and Improving Classroom Environment. School Science Review. 1994;75(272):107-13.

13. Chambers DW, Geissberger M, Leknius C. Association amongst factors thought to be important by instructors in dental education and perceived effectiveness of these instructors by students. European journal of dental education : official journal of the Association for Dental Education in Europe. 2004;8(4):147-51.

14. Irby $D$, Rakestraw P. Evaluating clinical teaching in medicine. Journal of medical education. 1981;56(3):181-6.

15. Vygotskii LS, Cole M. Mind in society : the development of higher psychological processes. Cambridge: Harvard University Press; 1978.

16. Hitz R, Driscoll A. Give Encouragement, Not Praise. Texas Child Care. 1994;17(4):2-

11.

17. Cantor N. The teaching-learning process. New York: Dryden Press; 1953.

18. Blatt B, Confessore S, Kallenberg G, Greenberg L. Verbal interaction analysis: viewing feedback through a different lens. Teaching and learning in medicine. 2008;20(4):329-33.

19. Crow S, Small R. Developing the Motivation within: Using Praise and Rewards Effectively2011.

20. Rogers CR, Freiberg HJ. Freedom to Learn: Prentice Hall; 1994. 
21. Lave J. Situated learning : legitimate peripheral participation: Cambridge [England] ; New York : Cambridge University Press, 1991.; 1991.

22. Robins LS, Gruppen LD, Alexander GL, Fantone JC, Davis WK. A predictive model of student satisfaction with the medical school learning environment. Academic medicine : journal of the Association of American Medical Colleges. 1997;72(2):134-9.

23. Wubbels T, Levy J. Do you know what you look like? Interpersonal relationships in education. Wubbels T, Levy J, editors. Oxford, England: Falmer Press/Taylor \& Francis, Inc; 1993.

24. Martin R. The One-Minute Teacher. Vocational Education Journal. 1987;62(5):40-1.

25. Samph T. Observer Effects on Teacher Verbal Classroom Behavior. Journal of Educational Psychology. 1976;68:736-41. 